\title{
Implications of ferrihydrite transformation for the fate of organic compounds in Precambrian iron formations
}

\author{
STANISLAV JELAVIC ${ }^{1}$, ANDREW MITCHELL ${ }^{2}$ AND \\ KARINA K. KRARUP SAND ${ }^{1}$ \\ ${ }^{1}$ University of Copenhagen \\ ${ }^{2}$ Aberystwyth University \\ Presenting Author: stanislav.jelavic@sund.ku.dk
}

The absence of organic compounds from Precambrian iron formations challenges the hypothesis that they were precipitated by microbial oxidation of $\mathrm{Fe}$ (II) to $\mathrm{Fe}(\mathrm{III})$. One of the proposed reasons for this absence is the mineralisation of organic compounds during the diagenesis and metamorphosis of IF (Posth et al., 2013). Here we test the hypothesis that some of the organic compounds have been lost even before the onset of diagenetic processes, during the transformation of primary iron (oxyhydr)oxides (Jelavić et al, 2020).

We used dynamic force spectroscopy to measure the bond strength between hematite and three functional groups commonly found in organic compounds (Figure 1a). We then chose a molecule with high density of hydroxyl groups that provide the strongest bond (glycerol), adsorbed it to ferrihydrite, transformed it directly to hematite and measured the loss of glycerol during the process (Figure 1b). We showed that glycerol is readily lost during the transformation. This loss of organic compounds is probably further enhanced by the grain coarsening of hematite during diagenetic and metamorphic processes and concomitant reactions in the microenvironment that result in secondary mineralization (Posth et al., 2013). Our results highlight that the absence of organic compounds in Precambrian iron formations is not suggestive of an abiotic origin.

Figure 1. a) Dynamic Force Spectroscopy spectra showing that the strongest bond between hematite (a product of ferrihydrite transformation) and common organic functional groups is hematite-OH, b) thermogravimetric spectra showing loss of glycerol during the transformation of ferrihydrite to hematite.

Jelavić, S., Mitchell, A.C. , Sand, K.K. (2020) Fate of organic compounds during transformation of ferrihydrite in iron formations. Geochemical Perspectives Letters 15, 25-29.

Posth, N.R., Köhler, I., Swanner, E.D., et al. (2013) Simulating Precambrian banded iron formation diagenesis. Chemical Geology 362, 66-73.
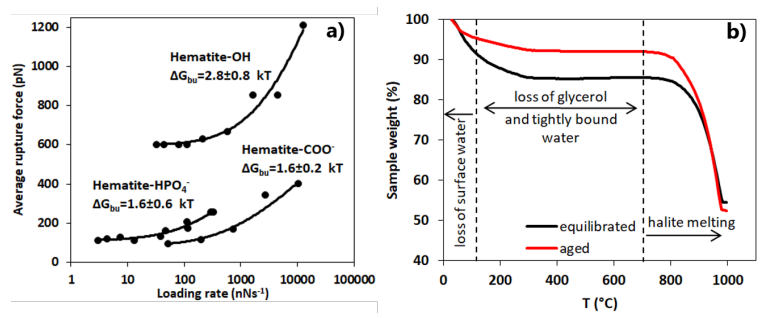